\title{
Eye movements and parafoveal word processing in reading Chinese
}

\author{
MiaO-Hsuan Yen \\ National Yang-Ming University, Taipei, Taiwan \\ JIE-LI TSAI \\ National Chengchi University, Taipei, Taiwan \\ and National Yang-Ming University, Taipei, Taiwan \\ OVID J.-L. TzEnG \\ National Yang-Ming University, Taipei, Taiwan \\ and Academia Sinica, Taipei, Taiwan \\ AND \\ DAISY L. Hung \\ National Yang-Ming University, Taipei, Taiwan
}

\begin{abstract}
In two experiments, a parafoveal lexicality effect in the reading of Chinese (a script that does not physically mark word boundaries) was examined. Both experiments used the boundary paradigm (Rayner, 1975) and indicated that the lexical properties of parafoveal words influenced eye movements. In Experiment 1, the preview stimulus was either a real word or a pseudoword. Targets with word previews, even unrelated ones, were more likely to be skipped than were those with pseudowords. In Experiment 2, all of the preview stimuli had the same first character as the target. Target words with same-morpheme previews were fixated for less time than were those with pseudoword previews, suggesting that morphological processing may be involved in extracting information from parafoveal words in Chinese reading. Together, the two experiments dealing with how words are processed in Chinese may provide some constraints on current computational models of reading.
\end{abstract}

Reading is a complicated and dynamic mental process in which readers actively move their eyes to extract information for comprehension. During each fixation, decisions need to be made concerning when to move the eyes and where to direct the gaze. Meanwhile, not only the fixated word, but also the word(s) in the parafovea are processed. Information extracted parafoveally facilitates processing on the subsequent fixation, which is referred to as the parafoveal preview benefit (Rayner, 1998). The range within which useful information can be extracted during a fixation is called the perceptual span (Rayner, 1998). For instance, the perceptual span extends 3 or 4 letters to the left and 14 or 15 letters to the right of the fixation point when English is read. In addition, it has been shown that factors such as word length, word frequency, and contextual predictability impact eye movement behavior (Calvo \& Meseguer, 2002; Kliegl, Grabner, Rolfs, \& Engbert, 2004; see Rayner, 1998, for a review).

Recently, computational models have been designed to account for the underlying mechanism (i.e., the coordination of visual, linguistic, and oculomotor systems) of eye movement control during reading (Engbert, Nuthmann,
Richter, \& Kliegl, 2005; Pollatsek, Reichle, \& Rayner, 2006; Reilly \& Radach, 2006; see Reichle, Rayner, \& Pollatsek, 2003, for comparisons among models). Broadly speaking, these models differ in their assumptions about (1) whether cognitive processing is the driving force that triggers eye movements and (2) whether words within the perceptual span are processed in a serial word-by-word fashion or in parallel as a function of a distributed processing gradient. Nevertheless, since these models are based on research with alphabetic scripts, most of them assume word-based processing (see S.-N.Yang \& McConkie, 2004, for a different view).

Evidence for word-based processing of alphabetic languages is provided by the preferred viewing location phenomenon (Rayner, 1979). The landing position distribution on a word is approximately a normal distribution slightly skewed to the left of the word center. In addition, as the distance between the prior fixation and the target word increases, the distribution shifts leftward and has greater variance (McConkie, Kerr, Reddix, \& Zola, 1988). McConkie et al. interpreted this finding as evidence that a word object is selected for the next saccade whereas the

O. J.-L.Tzeng, ovid@gate.sinica.edu.tw 
actual landing position is influenced by saccadic range error and random error. The existence of the preferred viewing location implies that certain information about the next word is extracted parafoveally (presumably, because words are delimited by interword spaces, at least the location and boundaries of the next word can be obtained) and is used to determine the next fixation location.

In contrast, there are scripts, such as Chinese, in which no cues for word boundaries are provided physically. Therefore, investigating how word processing is executed and how it influences eye movement behavior when Chinese text is read may challenge researchers to modify their general assumptions about eye movement behavior. Chinese is a morphosyllabic script. A character is a square-like unit, which corresponds to one syllable and usually has its own meaning(s), and a word is composed of either an independent character or multiple characters. According to the Chinese word corpus of Academia Sinica Taiwan (1998), which has 54,393 words, the proportion of one-, two-, three-, and four-character words are $9.5 \%, 65.6 \%, 12.4 \%$, and $11.6 \%$, respectively. Estimates of how many times readers encounter words of various lengths, as derived from the same corpus, show that single-character words appear $53.8 \%$ of the time and two-character words appear $42.2 \%$ of the time ( 10 million counts in total). Most of the multicharacter words are formed through compounding, with varying degrees of semantic transparency. Moreover, a single character may have multiple meanings, and this can further complicate the processing of compound words; words that share the same character may drastically differ in meaning. For example, 華 in 華僑 (overseas Chinese; 僑, people who live abroad) and 華語 (Chinese language; 語, language) has the meaning Chinese, whereas 華 in 華麗 (splendid; 麗, beautiful) and 華貴 (luxurious; 貴, valued and expensive) has the meaning magnificent. Thus, the processing of a word meaning cannot be regarded as equivalent to the processing of its constituent characters. Processing during reading may be further complicated by the mixed-word-length presentation of words in the absence of physical word boundaries. Therefore, the purpose of the present study was to investigate how Chinese readers extract information about words from a continuous character string and how word processing influences the pattern of eye movements during reading.

Basic eye movement behavior during the reading of Chinese has been investigated recently. In spite of radically different orthographies between Chinese and alphabetic scripts, most eye movement patterns are similar. First, as has been observed in other languages (see Rayner, 1998, for a review), the perceptual span of Chinese readers is asymmetric toward the reading direction. When reading from left to right, it extends, on average, one character to the left and three characters to the right of the fixation point (Inhoff \& Liu, 1998). ${ }^{1}$ The span may include one fixated word and one or two words in the parafovea. ${ }^{2}$ Also, similar to observations in other languages, Inhoff and Liu found that successive perceptual spans slightly overlap (i.e., saccade length is shorter than the perceptual span). This phenomenon suggests that Chinese readers fixate the area that is partially processed in the previous fixation, indicating parafoveal preprocessing and information integration between successive fixations. In fact, parafoveal preprocessing at the character level has been demonstrated. For example, previewing a character orthographically or phonologically similar to the target character yielded reduced fixation durations on the target (Liu, Inhoff, Ye, \& Wu, 2002; Tsai, Lee, Tzeng, Hung, \& Yen, 2004). Second, effects of various properties of words and their constituent characters on eye movement behavior have been observed. (1) For visual complexity (in terms of number of strokes), words composed of complicated characters were skipped less often and/or fixated longer than were words composed of less complicated characters (H.-M. Yang \& McConkie, 1999). (2) For lexical frequency, fixation durations on high-frequency words and words with high-frequency constituent characters were shorter than fixation durations on low-frequency counterparts (G. Yan, Tian, Bai, \& Rayner, 2006; H.-M. Yang $\&$ McConkie, 1999). Moreover, the character frequency effect was modulated by word frequency, being evident when word frequency was low but negligible when it was high. In addition, high-frequency words and words with a high-frequency initial character were skipped more often than low-frequency ones. (3) For contextual predictability, high- and medium-predictable target words were fixated more briefly and were skipped more often than low-predictable target words (Rayner, Li, Juhasz, \& Yan, 2005).

Although word frequency and predictability effects similar to those in other languages have been observed, the underlying mechanism of recognizing Chinese words embedded in a continuous character string may be different from that of recognizing words separated by spaces in most alphabetic scripts. During sentence reading, it remains unknown whether direct fixation is necessary for Chinese word processing or whether parafoveal word segmentation is possible for Chinese readers. In other words, does parafoveal processing reach the word level?

In contrast to the reliable evidence that readers of most alphabetic scripts adopt a word-based targeting strategy (i.e., direct their gaze to specific target words), there is no consistent evidence that Chinese readers adopt the same strategy. If Chinese words can be segmented parafoveally and then targeted as one unit, there should be a central tendency to land on a specific location on the word. However, H.-M. Yang and McConkie (1999) showed that there was no preferred viewing location for two-character words. There was no difference between the probability of landing on each character and the probability of landing on the space between characters. Furthermore, even when twocharacter words were divided into units that subtended visual angles that were the same as those of letters so that the length of a two-character word corresponded to that of a seven-letter word, Tsai and McConkie (2003) found a relatively flat landing position distribution in data collected from natural reading. Nevertheless, in a multiple regression analysis, their data revealed that the probability of landing on a character within the two character spaces to the right of the fixated character was high if it belonged to a low-frequency word. This finding suggests that attri- 
butes at the word level could influence the where decision. In addition, in a recent study, a preferred landing position at the word center was found for words that received single fixations (M. Yan, Richter, Shu, \& Kliegl, 2007).

Both the regression analysis of Tsai and McConkie (2003) and the results of M. Yan et al. (2007) suggest the possibility that Chinese readers obtain information at the word level parafoveally. Inhoff and Wu (2005) also have demonstrated that words within the perceptual span can be activated automatically. In their study, a critical fourcharacter string (C1234) was embedded in each sentence. This character string was either ambiguous or unambiguous. In the control condition, 專科畢業 (college graduate) was composed of two nonoverlapping contextually consistent words, 專科 (college; C12) and 畢業 (graduate; C34), whereas the combination of 科 and 畢 (C23) was not a word. In the ambiguous condition, 專科學生 (college student) contained three overlapping two-character words, including 專科 (college; C12), 科學 (science; C23), and 學生 (student; C34). The embedded word (科學, science) was contextually inconsistent-similar to design in predesignation in English - whereas the others were contextually consistent. A group of native speakers agreed that the word boundary should be placed between $\mathrm{C} 2$ and $\mathrm{C} 3$ in each ambiguous character string; that is, C12 and C34 were appropriate words. Even so, Inhoff and $\mathrm{Wu}$ found that contextually inconsistent combinations (C23; e.g., 科學 [science], which is contained in the characters that make up 專科學生 [college student]) were still activated, causing longer fixation durations for ambiguous character strings than for unambiguous strings (e.g., 專科畢業, college graduate). This result suggests that characters within the perceptual span are free to combine with adjacent characters to form possible words.

In addition, when a word is brought into the perceptual span, other words sharing the same constituent character (orthographic neighbors) may be activated. In fact, Tsai, Lee, Lin, Tzeng, and Hung (2006) observed an orthographic neighborhood size effect when Chinese sentences were read. Words with more neighbors were skipped more often and fixated more briefly than words with fewer neighbors. However, if the shared character has multiple meanings, how are different morphemes associated with the character processed? Zhou, Marslen-Wilson, Taft, and Shu (1999) proposed that when a compound word is presented, representations of the compound word and all morphemes associated with its constituent characters are activated initially. Later on, because of the competition among different morphemes and the interaction between the constituent morphemes and the whole compound word, only the appropriate morphemes remain activated. Their proposal was supported by a set of priming experiments. A two-character word (the prime) was presented for 57 or $200 \mathrm{msec}$ and was replaced by the target immediately afterward. When the stimulus onset asynchrony (SOA) was short, lexical decision time for the target (e.g., 華貴, luxurious) was shortened by presenting a word sharing one constituent character (either with a same morpheme [華麗, splendid] or a different morpheme [華僑, overseas Chinese]), relative to a word without any shared constitu- ent characters (完整, intact). However, the priming effect from the different-morpheme primes disappeared when the SOA was long, presumably because the competition among different morphemes was strong enough to counteract the facilitative effect. Their results indicate the time course of the activation of various representations associated with a word and its constituent characters. It is not known whether the mechanisms underlying isolated word recognition are the same as those involved in processing words in sentences.

In the present study, we investigated the possibility of parafoveal extraction of word-level information and its subsequent influence upon eye movements in Chinese, employing the boundary paradigm developed by Rayner (1975) in two experiments. In the boundary paradigm, the eye-contingent display change technique is employed. Participants are instructed to read sentences for comprehension while their eye movements are monitored simultaneously. A target is selected in each sentence, and an invisible boundary is set prior to the target as the trigger point for the display change. During the experiment, the target is initially replaced with a preview stimulus. After the participants move their eyes across the boundary, the preview stimulus immediately changes into the target stimulus. Furthermore, the properties that are shared between the preview stimulus and the target are manipulated. In contrast to a control condition wherein parafoveal preview is blocked with use of a mask, the potential extraction of shared properties in the experimental condition may reduce target-viewing durations or may otherwise influence eye movements. The boundary paradigm is therefore typically adopted to investigate the content of parafoveally processed information and how it is integrated between successive fixations. In the present study, the first experiment explored the possibility that whether a subset of the character string in the parafovea corresponds to a word can be determined. The second experiment was designed both to replicate the first experiment and to determine the features of the information extractable from a word in the parafovea, as well as the process by which this information is integrated with that extracted in the subsequent fixation.

\section{EXPERIMENT 1}

The boundary paradigm was used to investigate whether words can be processed parafoveally. Two-character words were used as the targets. There were three kinds of preview stimuli: the identical target word (identical word [ID] condition), a real word unrelated to the target word and inconsistent with the sentence context (unrelated word [UN] condition), and a pseudoword made up of two real characters (pseudoword [PS] condition). The existence of parafoveal word processing in Chinese would be supported if different eye movement behavior was found between the word (ID and UN) and the PS preview conditions. Furthermore, the level of processing could be inferred by comparing the ID and the UN conditions. If the processing reached the semantic level or needed contextual support, targets with UN previews 
would be skipped less often or fixated longer than those with ID previews.

Word frequency was also manipulated as an index of lexical processing. Inhoff and Rayner (1986) found that the visibility of words to the right of the fixated word interacted with the frequency of the parafoveal word (the target). The preview benefit effect for unmasked words, relative to masked ones, was larger for high-frequency targets than for low-frequency targets. Therefore, in the present experiment, we expected a word frequency effect and an interaction between preview type and target word frequency.

\section{Method}

Participants. Thirty college students at National Yang-Ming University were paid to participate in this experiment. All of them were native speakers of Chinese, with normal or corrected-to-normal vision.

Materials and Design. The boundary paradigm was adopted. The targets were two-character words (half of them were nouns and half of them were verbs). The two independent variables were preview type and target word frequency. As is shown in Table 1, there were three kinds of preview stimuli (i.e., the identical target word, a real word unrelated to the target word and inconsistent with the sentence context, and a pseudoword made up of two legal characters). According to the Chinese word corpus of Academia Sinica Taiwan (1998), every high-frequency word reappears between 18 and 400 times per every million words, whereas every low-frequency word reappears $1-1.5$ times per every million words.

For each target word, there was a matched unrelated real word from the same word class (noun or verb) with a similar word frequency $(F<1)$. The semantic relationship between the targets and the UN previews was assessed by 7 raters who did not participate in the main experiment. With a 5-point scale (1 for completely unrelated and 5 for highly related), the target-unrelated preview pairs were rated to be unrelated $(M=1.3, S D=0.46$; range, $1.0-3.1)$. Furthermore, the contextual fit of the target word and the unrelated word was assessed by another group of nonparticipating raters. The raters were presented with sentence fragments that included either the target word or the unrelated word. Then they rated how well the word fit into each sentence, with a 5-point scale ranging from 1 (the word does not fit into the sentence at all) to 5 (the word fits into the sentence very well). Each combination of the sentence fragment and the target/unrelated word was rated by 13 raters. The fit of the target word $(M=3.8, S D=$ $0.05)$ was significantly higher than that of the unrelated word $(M=$ $1.6, S D=0.04)[F(1,179)=1,113.88, p<.001]$.
PS previews were constructed by combining two characters randomly. The numbers of strokes of both constituent characters of the UN and the PS previews were matched with those of the target (both F's $<1$ for each constituent character). Moreover, at the character level, the triads were orthographically and phonologically dissimilar (at least nonhomophonic) and semantically unrelated. However, it was not easy to match the character frequency well among all six conditions while simultaneously holding to the criteria mentioned above. The ID and the UN previews for high-frequency targets tended to be composed of higher frequency characters than were the other preview stimuli. That is, both the main effect of target frequency and the interaction with preview type were significant $(p s<.05)$. Nevertheless, the main effect of preview type was not significant ( $p \mathrm{~s}>.13$ ).

The sentences contained 22-27 characters. The target words were embedded at the 11 th to 20 th character positions. ${ }^{3}$ The punctuation marks (if any) were at least two characters to the right or left of the target words. There was always a minimum of 5 characters succeeding the target. There were 30 trials in each condition. Sample sentences with their preview stimuli are shown in the Appendix.

Apparatus. The eye movements were recorded by an Eyelink I eyetracking system, manufactured by SR Research, with a sampling rate of $250 \mathrm{~Hz}$. The sentences were displayed on a ViewSonic PT795 monitor. In the experiment program, a set of VGA routines from a PCTSCOPE library (Tsai, 2001) was used to increase the vertical refresh rate of the display to $167 \mathrm{~Hz}$ in the resolution of $800 \times$ 600 pixels and to preload all images into VGA memory before each trial. Eye-contingent display changes were accomplished by combining the PCTSCOPE library for fast display change and the Eyelink software for detecting eye positions online. The overall time it took to acquire the current eye position and implement a display change was less than $16 \mathrm{msec}$. During this process, the movement of the eye across the boundary was detected within $10 \mathrm{msec}$. Then the experiment control program initiated the display change by switching images in $40.5 \mu \mathrm{sec}$. The display change was completed within one refresh cycle (range, $0-6 \mathrm{msec}$ ).

The sentences were presented in black on a light gray background on the display monitor. The screen resolution of the display monitor was $800 \times 600$ pixels. The size of the character was $24 \times 24$ pixels, and the size of the space between characters was $4 \times 24$ pixels. The viewing distance was $70 \mathrm{~cm}$, at which distance each character subtended $0.82^{\circ}$.

Procedure. The participants were instructed to read sentences normally for comprehension. They were told that there would be a comprehension test after some of the sentences. After setting up the eye cameras, a horizontal 3-point calibration was conducted to obtain the correspondence between the eye position recorded by the camera and the position of gaze on the screen. Then, 12 prac-

Table 1

Examples and Properties of the Preview Stimuli in Experiment 1

\begin{tabular}{lcccc}
\hline & & \multicolumn{3}{c}{ Preview Type } \\
\cline { 3 - 5 } & Target & Identical & Unrelated \\
& Frequency & Word (Target) & Word & Pseudoword \\
\hline Example & Low & 侍從 & 抗原 & 沸莊 \\
& High & 塑膠 & 監獄 & 傲廠 \\
Word meaning & Low & servant & antigen & - \\
& High & plastic & jail & - \\
Mean word frequency & Low & 1.2 & 1.2 & - \\
& High & 75.4 & 81.9 & - \\
Mean no. of strokes & Mean & 38.3 & 41.6 & - \\
(1st/2nd character) & Low & $11.3 / 11.0$ & $11.3 / 11.0$ & $11.3 / 11.0$ \\
& High & $11.7 / 11.8$ & $11.6 / 11.5$ & $11.7 / 11.8$ \\
Mean character frequency & Mean & $11.5 / 11.4$ & $11.5 / 11.3$ & $11.5 / 11.4$ \\
(1st/2nd character) & Low & $135.0 / 149.6$ & $195.4 / 314.2$ & $288.6 / 291.4$ \\
& High & $509.6 / 673.6$ & $559.2 / 457.9$ & $224.0 / 179.2$ \\
& Mean & $322.3 / 411.6$ & $377.2 / 386.0$ & $256.3 / 235.3$ \\
\hline
\end{tabular}

Note-Word frequency, 1 million words; character frequency, 1 million characters. 
tice trials were presented to ensure that the participants understood the task. During the experiment, each trial started with a fixation point presented in the location of the first character of the sentence. After the participants fixated on the fixation point, the experimenter pressed a button, and the sentence appeared on the screen. The participants read each sentence at their own pace and pressed a button to indicate that they had finished reading and understood the sentence. Then the sentence disappeared, and the fixation point for the next trial appeared. On about one third of the trials, a comprehension question followed the disappearance of the sentence. The participants had to decide whether the sentence in the comprehension test paraphrased the one they had just read. There was a break after 60 trials. Calibration was conducted every 20 trials, after breaks, and when there was a drift from the fixation point presented prior to the experimental sentence. The experiment lasted about $1 \mathrm{~h}$.

An invisible boundary was set at the first pixel of the space preceding the target word. At first, the target word was replaced by its corresponding preview stimulus. After the participants had moved their eyes across the boundary, the display change was implemented so that the sentence with the target word was presented. The participants were instructed to ignore any disturbance that might occur while they were reading the experimental sentences. In the interview after the main experiment, the participants were asked to estimate how often they had seen display changes. Some participants reported having seen something flash or change quite frequently. However, their eye movement records showed that the proportions of trials on which display changes had been triggered improperly (see the Results section for details) were not as high as their subjective estimations. In addition, most of the time, the participants did not know what had been presented before the display change.

\section{Results}

Three first-pass measures (i.e., first-fixation duration [FFD], gaze duration [GD] on the target, and skipping rate) were computed. Fixations on the target included fixations on the space prior to the target word and on the space between the constituent characters. FFD is the duration of the first first-pass fixation on the target independent of the number of fixations on that target. GD is the sum of the durations of all first-pass fixations on the target before leaving it. Both viewing duration measures are conditional on the target being fixated. Skipping rate is the proportion of trials in each condition on which the targets are not fixated during first-pass reading. We also computed the landing position on the target and the probability of rereading the target as supplementary measures. A 3 (preview type: identical word, unrelated word, or pseudoword) $\times 2$ (target frequency: low or high) ANOVA was performed for each measure separately.

There were three criteria for excluding trials from analysis. First, $0.7 \%$ of the trials were excluded because the participants blinked immediately before fixating or while fixating the target. Second, a set of criteria was set up to ensure that the experimental manipulation could be implemented properly and to reduce the chance that the participants might be aware of the display change, because the participants' awareness of display change might influence the preview benefit effect (White, Rayner, \& Liversedge, 2005). Thus, an additional $16.9 \%$ of the trials were excluded if (1) the boundary was crossed at the beginning or at the end of the trial; (2) among all fixations before boundary crossing, the prior fixation (i.e., the fixation immediately before boundary crossing) was not the closest fixation, relative to the boundary; or (3) the boundary was crossed after fixation onset because there was a drift during the prior fixation. Skipping rate and the probability of rereading the target were calculated for the remaining trials. Third, for the viewing duration measures and landing position calculations, trials on which there were no first-pass fixations on the targets were excluded. In addition, viewing durations shorter than $100 \mathrm{msec}$ or longer than 1,200 msec were excluded from analysis. This cutoff was applied to FFD and GD separately. The proportions of trials remaining for analyses were $68.3 \%$ for FFD, $68.2 \%$ for GD, and $68.4 \%$ for landing position on the target. There were at least 8 trials in each condition for each participant, and in most cases, there were more than 10 trials. The means and standard errors of skipping rate, FFD, GD, landing position, and the probability of rereading the target for each condition are shown in Table 2.

Skipping rate. The ANOVA revealed a significant main effect of preview type $\left[F_{1}(2,58)=7.06, M S_{\mathrm{e}}=56\right.$, $\left.p<.01 ; F_{2}(2,356)=6.21, M S_{\mathrm{e}}=157, p<.01\right]$ and a marginally significant main effect of target frequency $\left[F_{1}(1,29)=3.65, M S_{\mathrm{e}}=68, p=.066 ; F_{2}(1,178)=3.85\right.$, $\left.M S_{\mathrm{e}}=241, p=.051\right]$. However, there was no significant interaction (both $F \mathrm{~s}<1$ ). Targets with ID, UN, and PS previews were skipped $18.9 \%, 17.5 \%$, and $13.9 \%$ of the time, respectively. Post hoc pairwise comparisons revealed that the skipping rate in the PS condition was significantly lower than the skipping rate in the ID and the UN conditions ( $p<.01$ and $p<.05$, respectively). There was no difference between the ID and the UN conditions $(p=1)$. Furthermore, the $4.3 \%$ difference between word previews (ID and UN) and PS previews was significant $(p<.01)$. Regarding target word frequency, low-frequency targets were skipped $(15.6 \%)$ slightly less often than highfrequency targets $(17.9 \%)$.

Fixation duration on the target. The ANOVA revealed a significant main effect of preview type on FFD $\left[F_{1}(2,58)=28.02, M S_{\mathrm{e}}=1,428, p<.001 ; F_{2}(2,356)=\right.$ $\left.64.83, M S_{\mathrm{e}}=2,148, p<.001\right]$ and GD $\left[F_{1}(2,58)=23.09\right.$, $M S_{\mathrm{e}}=3,525, p<.001 ; F_{2}(2,356)=66.42, M S_{\mathrm{e}}=3,984$, $p<.001]$. The main effect of target frequency was marginally significant for FFD $\left[F_{1}(1,29)=3.88, M S_{\mathrm{e}}=818\right.$, $\left.p=.058 ; F_{2}(1,178)=3.80, M S_{\mathrm{e}}=2,380, p=.053\right]$ but was not significant for GD $\left[F_{1}(1,29)=2.47, M S_{\mathrm{e}}=\right.$ $\left.1,049, p=.127 ; F_{2}<1\right]$. The interaction was not significant (all $F_{\mathrm{s}}<1$ ). Post hoc pairwise comparisons revealed that targets with ID previews were fixated (FFD, $260 \mathrm{msec}$; GD, $286 \mathrm{msec}$ ) more briefly than those with UN previews (FFD, $303 \mathrm{msec}$; GD, $347 \mathrm{msec}$ ) and those with PS previews (FFD, $307 \mathrm{msec}$; GD, $353 \mathrm{msec}$ ) (all $p \mathrm{~s}<.001)$. There was no difference between UN previews and PS previews $(p s=1.0)$. In addition, the $-25-\mathrm{msec}$ difference in FFD and the -36-msec difference in GD between word previews (ID and UN) and PS previews were significant $(p s<.001)$. Regarding target word frequency, low-frequency targets were fixated (FFD, $294 \mathrm{msec}$; GD, $332 \mathrm{msec}$ ) slightly longer than high-frequency targets (FFD, $286 \mathrm{msec}$; GD, $325 \mathrm{msec})(p \mathrm{~s}>.05)$.

Landing position on the target. Throughout the analysis, the width of one character includes the space that precedes that character. It follows that the beginning of 
Table 2

Means and Standard Errors of Skipping Rate, First-Fixation Duration (FFD), Gaze Duration (GD), Landing Position, and Probability of Rereading the Target for Each Condition in Experiment 1

\begin{tabular}{|c|c|c|c|c|c|c|c|c|c|}
\hline \multirow[b]{3}{*}{ Measure } & \multirow{3}{*}{$\begin{array}{c}\text { Target } \\
\text { Frequency }\end{array}$} & \multicolumn{6}{|c|}{ Preview Type } & \multirow[b]{3}{*}{$M$} & \multirow[b]{3}{*}{$S E$} \\
\hline & & \multicolumn{2}{|c|}{$\begin{array}{c}\text { Identical } \\
\text { Word }\end{array}$} & \multicolumn{2}{|c|}{$\begin{array}{l}\text { Unrelated } \\
\text { Word }\end{array}$} & \multicolumn{2}{|c|}{ Pseudoword } & & \\
\hline & & $M$ & $S E$ & $M$ & $S E$ & $M$ & $S E$ & & \\
\hline \multirow[t]{3}{*}{ Skipping rate $(\%)$} & Low & 18.1 & 1.89 & 15.7 & 2.13 & 12.9 & 2.11 & 15.6 & 1.82 \\
\hline & High & 19.6 & 2.37 & 19.3 & 2.83 & 14.9 & 2.04 & 17.9 & 2.07 \\
\hline & Mean & 18.9 & 1.88 & 17.5 & 2.26 & 13.9 & 1.87 & & \\
\hline \multirow[t]{3}{*}{ FFD (msec) } & Low & 262 & 8.29 & 309 & 13.64 & 311 & 12.08 & 294 & 10.52 \\
\hline & High & 258 & 8.83 & 297 & 12.49 & 302 & 12.09 & 286 & 10.40 \\
\hline & Mean & 260 & 8.14 & 303 & 12.64 & 307 & 11.67 & & \\
\hline \multirow[t]{3}{*}{ GD (msec) } & Low & 290 & 12.16 & 352 & 19.74 & 355 & 17.26 & 332 & 15.23 \\
\hline & High & 283 & 11.46 & 342 & 18.47 & 350 & 18.01 & 325 & 14.77 \\
\hline & Mean & 286 & 11.27 & 347 & 18.75 & 353 & 17.24 & & \\
\hline \multirow{3}{*}{$\begin{array}{l}\text { Landing position } \\
\text { (characters) }\end{array}$} & Low & 1.08 & 0.03 & 1.04 & 0.02 & 1.02 & 0.03 & 1.05 & 0.02 \\
\hline & High & 1.07 & 0.03 & 1.03 & 0.03 & 1.01 & 0.03 & 1.04 & 0.03 \\
\hline & Mean & 1.07 & 0.02 & 1.04 & 0.02 & 1.02 & 0.03 & & \\
\hline \multirow{3}{*}{$\begin{array}{l}\text { Probability of } \\
\text { rereading the } \\
\text { target }(\%)\end{array}$} & Low & 6.7 & 1.27 & 11.7 & 1.55 & 9.2 & 1.47 & 9.2 & 1.16 \\
\hline & High & 4.6 & 1.05 & 10.4 & 1.41 & 7.3 & 1.12 & 7.4 & 0.78 \\
\hline & Mean & 5.6 & 0.96 & 11.0 & 1.28 & 8.3 & 1.16 & & \\
\hline
\end{tabular}

the target word is defined as the space preceding the first character of the target word. Landing position is the location of the fixation following a progressive interword saccade into the target, and it is measured relative to the beginning of the target word. There was a significant main effect of preview type $\left[F_{1}(2,58)=4.41, M S_{\mathrm{e}}=0.01, p<\right.$ $\left..05 ; F_{2}(2,356)=3.40, M S_{\mathrm{e}}=0.04, p<.05\right]$. Neither the main effect of target frequency nor the interaction was significant (all $F \mathrm{~s}<1$ ). Post hoc pairwise comparisons revealed that the landing position was significantly further into the target word in the ID condition (1.07 character position) than in the PS condition (1.02 character position) $(p<.01)$. Although the landing position on the target in the UN condition (1.04 character position) lay between those in the ID and the PS conditions, the differences were not significant (both $p \mathrm{~s}>.19$ ).

Probability of rereading the target. The proportion of trials in each condition on which there was at least one second-pass fixation on the target (regardless of whether or not the target was previously fixated) was computed as the probability of rereading the target. There was a significant main effect of preview type $\left[F_{1}(2,58)=10.75, M S_{\mathrm{e}}=41\right.$, $\left.p<.001 ; F_{2}(2,356)=12.28, M S_{\mathrm{e}}=109, p<.001\right]$. The main effect of target frequency was significant by participants and marginally significant by items $\left[F_{1}(1,29)=\right.$ $6.34, M S_{\mathrm{e}}=22, p<.05 ; F_{2}(1,178)=3.20, M S_{\mathrm{e}}=138$, $p=.075]$. There was no interaction (both $F \mathrm{~s}<1$ ). Targets with UN previews were revisited (11.0\%) more frequently than were those with ID previews $(5.6 \%)$ and PS previews $(8.3 \%)(p<.01$ and $p<.05$, respectively). The difference between the ID and the PS conditions was marginally significant by participants ( $p=.074)$ but was significant by items $(p<.05)$.

\section{Discussion}

There were two distinctive patterns concerning the main effect of preview type. First, the targets were skipped less frequently when the preview stimuli were pseudowords rather than words, even those that were contextually inappropriate. This indicates that on top of parafoveal character preprocessing (orthography and phonology), whether or not a subset of the character string in the perceptual span constitutes a word is also processed. Moreover, such parafoveal word processing influences the decision of where to direct the gaze (both saccade target selection and landing position on the target). Landing position was significantly further into the target in the ID condition than in the PS condition, although there was a trend that the landing position in the UN condition was situated between those in the other conditions. The pattern of results is analogous to that in recent studies addressing the possibility that linguistic properties, at least orthographic familiarity, of the parafoveal word influence the subsequent landing position (Radach, Inhoff, \& Heller, 2004; White \& Liversedge, 2004, 2006).

Second, targets with ID previews were fixated more briefly than were those with UN or PS previews. This confirms previous findings of parafoveal preview benefit effect and interfixation integration in the literature (see Rayner, 1998, for a review). If the target is visible parafoveally, parafoveal processing starts and then facilitates foveal processing. Since the UN preview was unrelated to the target and incompatible with the sentence context, there should not be any facilitative effect on target processing. Recently, a similar preview benefit effect from the parafoveal word was observed in reading simplified Chinese scripts (J. Yang, Wang, \& Rayner, 2007).

An effect of target frequency was observed in several measures. Low-frequency words were fixated longer and were less likely to be skipped, which is consistent with the results of previous studies (Tsai \& McConkie, 2003; G. Yan et al., 2006; H.-M. Yang \& McConkie, 1999). The interaction of target frequency and preview type was not significant. However, for skipping rate, contrasts among the three preview conditions seemed to be different for 
high- and low-frequency targets (see Table 2). Highfrequency targets were skipped equally often with ID and UN previews, whereas low-frequency targets were skipped most frequently with ID previews. Skipping rate for low-frequency targets with UN previews lay between those with ID previews and those with PS previews. This suggests that high-frequency words, even those incompatible with the sentence, can be processed parafoveally; in contrast, it is more difficult to process low-frequency words parafoveally if they are inconsistent with the context. In other words, the parafoveal preview benefit may be larger for high-frequency words. However, effect of preview type on the target-viewing durations (FFD and GD) remained regardless of target word frequency.

The observable differences in the patterns of preview effects indicate that the level of parafoveal word processing proceeds from an initial lexical activation to a deeper stage of processing that focuses on word meaning and contextual integration. The similarity between the parafoveal lexicality effects on skipping rate observed for the UN and ID previews suggests that words embedded in a series of characters - even contextually inappropriate and semantically unrelated - can be activated automatically at least in some conditions. This is reminiscent of the finding by Inhoff and $\mathrm{Wu}(2005)$ that the contextually inconsistent word (科學) embedded in two successive contextually consistent words (專科 and 學生) was activated, causing a longer fixation duration for the critical ambiguous fourcharacter string (專科學生) than for the unambiguous one. At the same time, this effect of preview type on skipping rate also suggests that saccade target selection may be made according to overall lexical activity (Grainger \& Jacobs, 1996) and general familiarity, which may reflect a combined effect of character and word frequencies, rather than the full identification of the skipped word. If a subset of the character string in the parafovea is a familiar combination that exists in lexical memory, lexical access starts in the parafovea and continues during the subsequent fixation. If the character string is unfamiliar, it requires foveal examination. However, as long as the character string exists in the mental lexicon, saccade target selection is somewhat indifferent as to what will be retrieved from lexical memory. Nevertheless, processing of the parafoveal word continues during subsequent fixations, and, as compared with the ID preview, no facilitation on target processing (if it was fixated) from previewing an unrelated word was observed. In addition, the probability of rereading the target was the highest in the UN condition, indicating a conflict in integrating the UN preview with the sentence.

The pattern of the preview effect on target-viewing durations should be interpreted with caution. Potential effects of display change may be different among conditions. When the boundary was crossed, the UN and the PS previews were replaced by the visually different target words, whereas the ID preview was replaced by itself. Thus, performance may be altered by visual disruption in the UN and PS conditions, rather than facilitation from the identical previews. Nevertheless, it has been demonstrated that the disruption in studies using the eye-contingent display change technique is caused by the masking of use- ful linguistic information, rather than by physical flicker (Inhoff, Starr, Liu, \& Wang, 1998). In addition, the effect of preview type on skipping rate is not compromised by the effect of boundary-triggered display change, since the decision to fixate upon a target or move on occurs before the boundary is crossed. Nonetheless, the second experiment was designed to investigate how words are processed parafoveally and how information is integrated between fixations with similar effects of display change among preview conditions.

\section{EXPERIMENT 2}

As in Experiment 1, the boundary paradigm was adopted, and the target was a two-character word. In this experiment, the preview stimuli shared the same first character with their target in each trial. The shared first character had multiple meanings. There were three kinds of preview stimuli: same-morpheme (SM) preview, different-morpheme (DM) preview, and PS preview. The meaning of the shared first character of the target was the same as that of its SM preview but was different from that of its DM preview. Because the same character was presented parafoveally, any difference in eye movement behavior among preview conditions had to result from word processing. Therefore, if a preview benefit in the word preview conditions (SM and/or DM), as compared with the PS preview condition, was observed, the parafoveal lexicality effect would be supported and replicated. Moreover, how a multicharacter word is processed parafoveally was investigated in this experiment. If morphological processing is involved in extracting information from the parafoveal word, the pattern of results should be similar to the findings of Zhou et al. (1999). In addition, since the second character of the preview stimuli, which was different from that of the target word, was changed after boundary crossing in all the conditions, the potential effect of the display change on the pattern of results should be attenuated when preview conditions are compared.

\section{Method}

Participants. Thirty college and graduate students at National Yang-Ming University were paid to participate in the experiment. All of them are native speakers of Chinese, with normal or corrected-to-normal vision. Four of them had participated in the first experiment more than 5 months earlier.

Materials and Design. The boundary paradigm was adopted. As is shown in Table 3, the target was a two-character word (e.g., 戒菸, to quit smoking; 菸, tobacco). The preview stimuli were two-character strings sharing the first character (戒) with the target. There were three kinds of preview stimuli, two words and one pseudoword (戒料). For the two word previews, one (戒除, to give up a habit; 除, to get rid of) shared a common morpheme (to quit or give up) with the target, while the other (戒備, to guard against; 備, to be equipped) did not.

For each trial, three words that shared the same first character were chosen. They were in the same word class (noun or verb) and were similar in terms of word frequency $(F<1 ; M=2.9$ per million; $S D=3.7$; range, $0.1-23.2$ per million). Five raters who did not participate in the experiment compared the meaning of the first character of the SM preview and the DM preview separately with that of the target with a 5-point rating scale, where 1 indicated same in meaning and 5 indicated different in meaning. The mean rating values for the SM preview-target pairs and for the DM preview-target pairs were 
Table 3

Examples and Properties of the Target and the Preview Stimuli in Experiment 2

\begin{tabular}{lcccc}
\hline & & \multicolumn{3}{c}{ Preview Type } \\
\cline { 3 - 5 } & Target & $\begin{array}{c}\text { Same } \\
\text { Morpheme }\end{array}$ & $\begin{array}{c}\text { Different } \\
\text { Morpheme }\end{array}$ & Pseudoword \\
\hline Example & 戒菸 & 戒除 & 戒備 & 戒料 \\
Meaning of the shared character & quit & quit & guard & - \\
Word meaning & & \multicolumn{3}{c}{ against } \\
Mean word frequency & to quit & to give up & to guard & - \\
Mean no. of strokes (2nd character) & smoking & a habit & against & - \\
Mean character frequency (2nd character) & 840.5 & 3.0 & 2.9 & 11.2 \\
\hline
\end{tabular}

Note-Word frequency, 1 million words; character frequency, 1 million characters.

1.2 and 4.2 , respectively. The difference was significant $(p<.001)$. Although different character meanings may be associated with different pronunciations or different syntactic categories, the triads were carefully chosen so that they differed only in character meaning. Both the numbers of strokes and the frequencies of the second characters of all the preview stimuli were matched (both $F$ s $<1$ ).

The rules for constructing experimental sentences were the same as those in the first experiment. There were 26 trials in each condition. Twenty-one additional trials, whose contrasts in semantic rating values of character meaning were not large enough, were kept as filler trials.

Apparatus and Procedure. The apparatus was the same as that in Experiment 1. The procedure was almost the same, except that the length of the experiment was shorter. There was only one break after 50 trials. The experiment lasted about $40 \mathrm{~min}$. The instruction to ignore any disturbance during reading was given to the participants. In addition, subjective estimations about their awareness of display changes that were similar to those in Experiment 1 were obtained.

\section{Results}

Following the same criteria as those in Experiment 1, $0.7 \%$ of the trials were excluded because the participants blinked immediately before fixating or while fixating the target. In addition, $16.9 \%$ of the trials were excluded to ensure that the experimental manipulation was implemented appropriately (see Experiment 1 for details). The proportions of trials that remained for analyses were $68.3 \%$ for FFD, $68.2 \%$ for GD, and $68.7 \%$ for landing position on the target. There were at least 8 trials in each condition for each participant, and in most cases there were more than 10 trials. An ANOVA was performed for each measure separately. The means and standard errors of skipping rate, FFD, GD, and landing position for each condition are shown in Table 4.

Table 4

Means and Standard Errors of Skipping Rate, First-Fixation Duration (FFD), Gaze Duration (GD), and Landing Position for Each Condition in Experiment 2

\begin{tabular}{|c|c|c|c|c|c|c|}
\hline \multirow[b]{3}{*}{ Measure } & \multicolumn{6}{|c|}{ Preview Type } \\
\hline & \multicolumn{2}{|c|}{$\begin{array}{c}\text { Same } \\
\text { Morpheme } \\
\end{array}$} & \multicolumn{2}{|c|}{$\begin{array}{c}\text { Different } \\
\text { Morpheme }\end{array}$} & \multicolumn{2}{|c|}{ Pseudoword } \\
\hline & $M$ & $S E$ & $M$ & $S E$ & $M$ & $S E$ \\
\hline Skipping rate (\%) & 17.8 & 2.69 & 15.1 & 2.50 & 17.1 & 2.96 \\
\hline FFD (msec) & 260 & 6.98 & 271 & 7.81 & 279 & 7.55 \\
\hline GD (msec) & 287 & 9.82 & 302 & 11.63 & 317 & 11.64 \\
\hline $\begin{array}{l}\text { Landing position } \\
\text { (characters) }\end{array}$ & 1.00 & 0.03 & 1.05 & 0.03 & 1.04 & 0.03 \\
\hline
\end{tabular}

Skipping rate. The main effect of preview type on skipping rate was not significant $\left[F_{1}(2,58)=1.20, M S_{\mathrm{e}}=\right.$ $\left.51, p>.30 ; F_{2}(2,154)=2.05, M S_{\mathrm{e}}=148, p>.13\right]$.

Fixation duration on the target. The ANOVA revealed a significant main effect of preview type on FFD $\left[F_{1}(2,58)=6.81, M S_{\mathrm{e}}=376, p<.01 ; F_{2}(2,154)=4.69\right.$, $\left.M S_{\mathrm{e}}=1,458, p<.05\right]$ and GD $\left[F_{1}(2,58)=8.12, M S_{\mathrm{e}}=\right.$ $\left.840, p<.01 ; F_{2}(2,154)=6.95, M S_{\mathrm{e}}=2,742, p<.01\right]$. Post hoc pairwise comparisons revealed that fixation durations on targets with SM previews (FFD, $260 \mathrm{msec}$; GD, $287 \mathrm{msec}$ ) were significantly shorter than those with PS previews (FFD, $279 \mathrm{msec}$; GD, $317 \mathrm{msec}$ ) (both $p$ s < $.01)$. The differences between the DM condition (FFD, $271 \mathrm{msec}$; GD, $302 \mathrm{msec}$ ) and the other conditions were not significant (all $p \mathrm{~s}>.13$ ).

Landing position on the target. The main effect of preview type on landing position was not significant $\left[F_{1}(2,58)=1.13, M S_{\mathrm{e}}=0.015, p>.33 ; F_{2}(2,154)=\right.$ $\left.1.07, M S_{\mathrm{e}}=0.041, p>.34\right]$.

\section{Discussion}

The primary finding of this experiment is that fixation durations on the targets with SM previews were significantly shorter than those with PS previews. Since the first character of the target word (which was identical to that of the previews) was available parafoveally, this result suggests that the second character of the preview stimuli was processed to disambiguate which parts of the previewed character string corresponded to words. Thus, the parafoveal lexicality effect was confirmed in this experiment, with a similar effect of display change (if any) among conditions.

There was a numerical trend showing that the mean fixation duration on the targets in the DM preview condition lay between those in the other preview conditions (SM and PS), although the differences were not significant. This pattern of results may reveal the complexity underlying parafoveal processing of words that consist of characters with multiple meanings. As was suggested by the study of Zhou et al. (1999), when a compound word is presented, all morphemes associated with its constituent characters are activated initially, but only the appropriate morphemes remain activated later on. Thus, the priming effect from DM primes disappeared when the SOA was long. In the present experiment, a similar pattern of 
Table 5

Means and Standard Errors of First-Fixation Duration (FFD) and Gaze Duration (GD) on the Target for Each Preview Type As a Function of Prior Fixation Duration in Experiment 2

\begin{tabular}{|c|c|c|c|c|c|c|c|}
\hline \multirow[b]{3}{*}{ Measure } & \multirow{3}{*}{$\begin{array}{c}\text { Prior } \\
\text { Fixation } \\
\text { Duration }\end{array}$} & \multicolumn{6}{|c|}{ Preview Type } \\
\hline & & \multicolumn{2}{|c|}{$\begin{array}{c}\text { Same } \\
\text { Morpheme }\end{array}$} & \multicolumn{2}{|c|}{$\begin{array}{c}\text { Different } \\
\text { Morpheme }\end{array}$} & \multicolumn{2}{|c|}{ Pseudoword } \\
\hline & & $M$ & $S E$ & $M$ & $S E$ & $M$ & $S E$ \\
\hline \multirow[t]{2}{*}{ FFD (msec) } & Short & 254 & 5.84 & 250 & 5.54 & 269 & 6.76 \\
\hline & Long & 267 & 6.02 & 290 & 7.62 & 286 & 5.84 \\
\hline \multirow[t]{2}{*}{ GD (msec) } & Short & 276 & 8.42 & 275 & 8.29 & 301 & 8.78 \\
\hline & Long & 297 & 8.45 & 330 & 10.32 & 334 & 10.23 \\
\hline
\end{tabular}

results was observed when the data were partitioned according to the median prior fixation duration for each item (cutoff point: $M=220, S D=22.9$ ). Five items were excluded from analyses because of empty cells. As is shown in Table 5, there was a marginally significant interaction between prior fixation duration and preview type for FFD on the target $\left[F_{2}(2,144)=2.933, M S_{\mathrm{e}}=\right.$ $2,691, p=.056]$. Whereas the differences between the SM and the PS conditions were similar regardless of prior fixation duration (short, $-15 \mathrm{msec}$; long, $-19 \mathrm{msec}$ ), the difference between the DM and the PS conditions was marginally significant when the prior fixation duration was short $(-19 \mathrm{msec})$ but was negligible when the duration was long $(4 \mathrm{msec})$. A similar pattern was observed for GD on the target as well. Thus, the results from this supplementary analysis provide an indication of the evolution of the level of parafoveal processing. However, when the parafoveal morphological effect emerges may depend on the difficulty of foveal (Henderson \& Ferreira, 1990, 1993 ) and parafoveal processing at both the character and the word levels; hence, it may differ from trial to trial. This is one possible reason why viewing duration measures in the DM condition were in between those in the other two conditions.

The skipping rate was almost the same among the three preview conditions, which was not expected. This result reflects the fact that a number of factors influence target skipping. In previous studies of Chinese reading, visual and linguistic factors at the character and the word levelsnumber of strokes, frequency, and predictability-have been found to influence skipping rate over a character or a word (Rayner et al., 2005; Tsai \& McConkie, 2003; G. Yan et al., 2006; H.-M. Yang \& McConkie, 1999). Since the effect of preview type was stronger when the target was a high-frequency word in Experiment 1, it follows that the absence of a preview effect in Experiment 2 might result from the relatively low frequency (less than 25 times/million words) of the target words used. To further account for the disparity with the outcome of Experiment 1, three other manipulations distinct to Experiment 2 may have had an impact upon the results: The shared first character of the previews was a reasonable continuation of the sentence; the manipulated second character of the preview stimulus was further into the parafovea; and the visual complexity and frequency of the second characters were matched among conditions. Nevertheless, the skipping rate was sensitive to the frequency of the shared first character. After the data were split into two parts according to the median character frequency (371 per million; range, 30-3,548 per million), an effect of character frequency on skipping rate was observed $\left[F_{1}(1,29)=8.94\right.$, $M S_{\mathrm{e}}=209, p<.01 ; F_{2}(1,76)=8.77, M S_{\mathrm{e}}=175, p<$ $.01]$. However, there was no interaction between preview type and character frequency $\left(F_{1}<1 ; F_{2}<2, p>.24\right){ }^{4}$

To summarize, the results of this experiment suggest that the second character of the preview stimulus was processed to determine whether the character string was a word or not. Thus, the parafoveal lexicality effect was replicated. Furthermore, the results suggest that characters within the perceptual span activate the representations of the words they form. Initially, all morphemes associated with the constituent characters are activated. Through competition among different morphemes and interaction between words and characters, only the appropriate morphemes remain activated. Thus, a preview benefit from the SM preview was observed, whereas the benefit from the DM preview was not.

\section{GENERAL DISCUSSION}

The purpose of this study was to investigate the parafoveal extraction of word-level information from written Chinese in the absence of visual cues for word boundary. In two experiments, a parafoveal lexicality effect was observed by using the boundary paradigm. The varied effects of preview may reveal the evolution of parafoveal processing between the perceptual introduction of a word and its full integration into sentence meaning. First of all, the observation that word previews (especially high-frequency ones) were more likely to lead to skipping of the preview than were PS previews in Experiment 1 indicates that parafoveal preprocessing reaches the word level. Also, the lexicality of the parafoveal stimulus can influence its fixation probability. However, as will be discussed in detail later, the level of processing at this stage might be overall lexical activity, rather than full identification, because there was no difference between ID previews and UN word previews in skipping rate over the target. This difference was reflected on subsequent target-viewing durations (if fixated) and rereading probability, suggesting difficulty in subsequent information integration. To clarify what kind of information about the parafoveal word was integrated between successive fixations, a two-character string sharing the first character with the target was presented parafoveally in Experiment 2. Fixation durations on the target in the SM preview condition were the shortest and were significantly different from those in the PS preview condition. Fixation durations on the target in the DM preview condition were midway between those in the other two conditions. This result suggests that all morphemes associated with characters within the perceptual span are activated initially. If the combination of adjacent characters exists in lexical memory, the representation of the word is activated and interacts with all associated morphemes. Subsequently, only the representation of the word and its constituent morphemes remain activated, which results in the reliable preview benefit in the SM preview condition. 
The level of parafoveal processing depends on the distance between the target and the location of the prior fixation (launch distance). This is evident from the observation that the main effects of preview type in both experiments were modulated by launch distance (see Table 6). In Experiment 1, the effect of preview type on skipping rate (i.e., word previews were more likely to be skipped than were PS previews) was found only when the launch distance was short (within 1.3 character spaces on average, $S D=0.3$ ). This is consistent with the findings of Tsai and McConkie (2003). In their study, the probability of landing on a character that was one or two characters away from the fixation point could be accounted for mainly by the frequency of the word to which it belonged. However, the effect of the visual complexity of the character on its fixation probability extended up to three character spaces away from the fixation point. In other words, word information was extracted from a subset of the character string located closer to the fixation point, whereas only information at the character level could be extracted from stimuli located further away from the fixation point. This pattern of data suggests that the level of parafoveal processing decreases as the eccentricity of the target from the prior fixation location increases. Similarly, the effect of preview type on fixation durations was larger when the launch distance was short than when it was long, in both experiments. These results are also consistent with the finding of Radach and Heller (2000) that the effectiveness of preview benefit depends on launch distance. Consistent with this argument, the effect of preview type on skipping rate was negligible in Experiment 2, probably because the key manipulation was on the second character of the preview stimuli, which was further into the parafovea. Moreover, the modulation of launch distance on the effect of preview type in Experiment 2 seemed to be less robust, as compared with that in Experiment 1.

The parafoveal lexicality effect was demonstrated by the effect of preview type on skipping rate in the first experiment. To what extent was a word processed parafoveally before it was skipped? In general, there are two views concerning this issue. First of all, in the E-Z Reader model framework (Pollatsek et al., 2006), most skipped words are recognized, to some degree, parafoveally. There are two stages in the word identification module-namely, the familiarity check (e.g., early orthographic and phonological processing) and the completion of lexical access (full identification). When the first stage of processing the attended word (word $n$, corresponding to the fixated word most of the time) is completed, a saccade to the next word $(n+1)$ is programmed. When the second stage is completed, attention shifts to the next word, and parafoveal word processing starts. If the familiarity check of word $n+1$ is completed during the labile stage of saccade programming, the original saccade to word $n+1$ is canceled (the word is skipped) and replaced by a saccade to word $n+2$. Thus, at least the first stage of processing word $n+1$ is completed before it is skipped. ${ }^{5}$ Adapting the explanatory framework of the E-Z Reader model to the finding of the present study, it is possible that the familiarity of the parafoveal stimuli was checked to determine whether a subset of parafoveal characters corresponded to a word, which in turn influences skipping rate.

The second theoretical viewpoint offered - that skipping is mainly caused by coarse visual processing - may not be appropriate for Chinese reading. Brysbaert and Vitu (1998) proposed that readers make an educated guess about whether the parafoveal word can be identified within the current fixation on the basis of the eccentricity and the length of the parafoveal word. If the probability of identifying the parafoveal word is high, it is more likely to be skipped. Because there is no physical cue for word boundaries in written Chinese, we speculate that Chinese readers may rely more on linguistic information than on pure visual information to determine the next saccade target. Clearly, more studies in Chinese are necessary to clarify the mechanism underlying skipping in the reading of Chinese. ${ }^{6}$

The existence of a parafoveal lexicality effect while a series of characters without cues for word boundaries are read suggests that a model of eye movement control in the reading of Chinese sentences should incorporate not only character units, but also word units. In fact, Rayner, Li, and Pollatsek (2007) have successfully extended the E-Z Reader model to Chinese reading while maintaining the assumptions applied to alphabetic languages (e.g., holding the word-targeting strategy and treating characters as orthographic units). The simulation result reflects the general similarity and subtle discrepancy between English and Chinese reading. Nevertheless, further investigation is needed to clarify the time course of both character and word processing, as well as how their properties and processing influence the when and where decisions. Further-

Table 6

Means and Standard Errors of Skipping Rate, First-Fixation Duration (FFD), and Gaze Duration (GD) on the Target for Each Preview Type As a Function of Launch Distance in Experiments 1 and 2

\begin{tabular}{|c|c|c|c|c|c|c|c|c|c|c|c|c|c|}
\hline \multirow[b]{3}{*}{ Measure } & \multirow{3}{*}{$\begin{array}{c}\text { Launch } \\
\text { Distance }\end{array}$} & \multicolumn{6}{|c|}{ Experiment 1} & \multicolumn{6}{|c|}{ Experiment 2} \\
\hline & & \multicolumn{2}{|c|}{$\begin{array}{l}\text { Identical } \\
\text { Word }\end{array}$} & \multicolumn{2}{|c|}{$\begin{array}{l}\text { Unrelated } \\
\text { Word }\end{array}$} & \multicolumn{2}{|c|}{ Pseudoword } & \multicolumn{2}{|c|}{$\begin{array}{c}\text { Same } \\
\text { Morpheme }\end{array}$} & \multicolumn{2}{|c|}{$\begin{array}{c}\text { Different } \\
\text { Morpheme }\end{array}$} & \multicolumn{2}{|c|}{ Pseudoword } \\
\hline & & $M$ & $S E$ & $M$ & $S E$ & $M$ & $S E$ & $M$ & $S E$ & $M$ & $S E$ & $M$ & $S E$ \\
\hline \multirow{2}{*}{ Skipping rate (\%) } & Short & 29.4 & 2.91 & 26.5 & 3.51 & 19.9 & 2.62 & 30.0 & 4.15 & 25.9 & 4.25 & 27.0 & 4.34 \\
\hline & Long & 8.5 & 1.33 & 7.9 & 1.52 & 8.7 & 1.66 & 4.4 & 1.49 & 5.6 & 1.62 & 6.2 & 2.05 \\
\hline \multirow[t]{2}{*}{ FFD (msec) } & Short & 259 & 8.52 & 315 & 14.02 & 321 & 12.58 & 257 & 7.58 & 270 & 9.37 & 284 & 7.86 \\
\hline & Long & 262 & 8.54 & 291 & 11.39 & 294 & 11.56 & 264 & 8.12 & 272 & 8.08 & 273 & 9.18 \\
\hline \multirow[t]{2}{*}{ GD (msec) } & Short & 276 & 11.63 & 358 & 19.56 & 368 & 18.04 & 278 & 10.19 & 299 & 12.50 & 324 & 13.42 \\
\hline & Long & 295 & 13.06 & 340 & 19.55 & 337 & 17.14 & 296 & 12.26 & 302 & 13.82 & 309 & 12.60 \\
\hline
\end{tabular}


more, the fact that Chinese characters have their own representations, such as orthographical form and meaning, suggests that how the processing of characters and words interact with each other should be considered.

This raises the question of whether the generally assumed word-based processing in the reading of most alphabetic scripts is applicable to Chinese reading. In addition, the long-debated serial/parallel issue (Starr \& Rayner, 2001) may be more complicated in Chinese. Indeed, reading is a complex perceptual process that occurs in one subset of the entire visual field. Since the perceptual process of linguistic extraction differs across languages, cross-language comparisons are essential for understanding how humans establish a visual-sampling routine that solves various visual and linguistic problems.

To conclude, parafoveal word processing in reading Chinese was demonstrated in two experiments with the boundary paradigm. Since there appear to be neither visual nor linguistic clues to delineate words in Chinese, preprocessing of parafoveal words makes reading more efficient. Overall lexical activity influences whether the character string in the parafovea needs foveal inspection. Words within the perceptual span are automatically activated through the links from their constituent characters. Moreover, interaction between characters and words and competition among all morphemes associated with the constituent characters may be involved in parafoveal word processing and interfixation integration.

\section{AUTHOR NOTE}

This study was supported by a grant from Taiwan's National Science Council (NSC 93-2413-H-010-003). The revision was completed when the first author was a visiting scholar at Florida State University under support from Taiwan's National Science Council (NSC-0952917-I-010-001). We thank Keith Rayner, Albrecht Inhoff, and two anonymous reviewers for helpful comments on an earlier version of the manuscript. We are grateful to Mary Louise Kean, Ralph Radach, and Ronan Reilly for helpful discussions and comments on earlier versions of the manuscript. Correspondence concerning this article should be addressed to O. J.-L. Tzeng, Laboratories for Cognitive Neuroscience, Institute of Neuroscience, National Yang-Ming University, Pei-Tou, Taipei 112, Taiwan (e-mail: ovid@gate.sinica.edu.tw).

\section{REFERENCES}

Academia Sinica Taiwan (1998). Academia Sinica balanced corpus (Version 3) [CD-ROM]. Taipei, Taiwan: Academia Sinica, Chinese Knowledge and Information Processing Group.

Brysbaert, M., \& Vitu, F. (1998). Word skipping: Implications for theories of eye movement control in reading. In G. Underwood (Ed.), Eye guidance in reading and scene perception (pp. 125-147). Amsterdam: Elsevier.

Calvo, M. G., \& Meseguer, E. (2002). Eye movements and processing stages in reading: Relative contribution of visual, lexical, and contextual factors. Spanish Journal of Psychology, 5, 66-77.

Drieghe, D., Rayner, K., \& Pollatsek, A. (2005). Eye movements and word skipping during reading revisited. Journal of Experimental Psychology: Human Perception \& Performance, 31, 954-959.

Engbert, R., Nuthmann, A., Richter, E. M., \& Kliegl, R. (2005). SWIFT: A dynamical model of saccade generation during reading. Psychological Review, 112, 777-813.

Grainger, J., \& JACOBS, A. M. (1996). Orthographic processing in visual word recognition: A multiple read-out model. Psychological Review, 103, 518-565.

Henderson, J. M., \& Ferreira, F. (1990). Effects of foveal processing difficulty on the perceptual span in reading: Implications for attention and eye movement control. Journal of Experimental Psychology: Learning, Memory, \& Cognition, 16, 417-429.

Henderson, J. M., \& Ferreira, F. (1993). Eye movement control during reading: Fixation measures reflect foveal but not parafoveal processing difficulty. Canadian Journal of Experimental Psychology, 47, 201-221.

INHOFF, A. W., \& LiU, W. (1998). The perceptual span and oculomotor activity during the reading of Chinese sentences. Journal of Experimental Psychology: Human Perception \& Performance, 24, 20-34

InHoff, A. W., \& RaYNer, K. (1986). Parafoveal word processing during eye fixations in reading: Effects of word frequency. Perception \& Psychophysics, 40, 431-439.

InHOFF, A. W., STARR, M. [S.], LIU, W., \& WANG, J. (1998). Eye-movementcontingent display changes are not compromised by flicker and phosphor persistence. Psychonomic Bulletin \& Review, 5, 101-106.

InHofF, A. W., \& Wu, C. (2005). Eye movements and the identification of spatially ambiguous words during Chinese sentence reading. Memory \& Cognition, 33, 1345-1356.

KLIEGL, R., \& ENGBERT, R. (2005). Fixation durations before word skipping in reading. Psychonomic Bulletin \& Review, 12, 132-138.

Kliegl, R., Grabner, E., Rolfs, M., \& Engbert, R. (2004). Length, frequency, and predictability effects of words on eye movements in reading. European Journal of Cognitive Psychology, 16, 262-284.

LiU, W., INhoFf, A. W., Ye, Y., \& Wu, C. (2002). Use of parafoveally visible characters during the reading of Chinese sentences. Journal of Experimental Psychology: Human Perception \& Performance, 28, 1213-1227.

McConkie, G. W., Kerr, P. W., ReddiX, M. D., \& Zola, D. (1988). Eye movement control during reading: I. The location of initial eye fixations on words. Vision Research, 28, 1107-1118.

Nuthmann, A., Engbert, R., \& Kliegl, R. (2005). Mislocated fixations during reading and the inverted optimal viewing position effect. Vision Research, 45, 2201-2217.

Pollatsek, A., Reichle, E. D., \& Rayner, K. (2006). Tests of the E-Z Reader model: Exploring the interface between cognition and eyemovement control. Cognitive Psychology, 52, 1-56.

Radach, R., \& Heller, D. (2000). Relations between spatial and temporal aspects of eye movement control. In A. Kennedy, R. Radach, D. Heller, \& J. Pynte (Eds.), Reading as a perceptual process (pp. 165-191). Amsterdam: Elsevier.

RADACH, R., INHOFF, A. W., \& Heller, D. (2004). Orthographic regularity gradually modulates saccade amplitudes in reading. European Journal of Cognitive Psychology, 16, 27-51.

RAYNER, K. (1975). The perceptual span and peripheral cues in reading. Cognitive Psychology, 7, 65-81.

RAYNER, K. (1979). Eye guidance in reading: Fixation locations within words. Perception, 8, 21-30.

RAYNER, K. (1998). Eye movements in reading and information processing: 20 years of research. Psychological Bulletin, 124, 372-422.

RAYNER, K., Li, X., Juhasz, B. J., \& Yan, G. (2005). The effect of word predictability on the eye movements of Chinese readers. Psychonomic Bulletin \& Review, 12, 1089-1093.

Rayner, K., LI, X., \& Pollatsek, A. (2007). Extending the E-Z Reader model of eye movement control to Chinese readers. Cognitive Science, 31, 1021-1034.

Reichle, E. D., Rayner, K., \& Pollatsek, A. (2003). The E-Z Reader model of eye-movement control in reading: Comparisons to other models. Behavioral \& Brain Sciences, 26, 445-476.

REILLY, R. G., \& RADACH, R. (2006). Some empirical tests of an interactive activation model of eye movement control in reading. Cognitive Systems Research, 7, 34-55.

STARR, M. S., \& RAYNER, K. (2001). Eye movements during reading: Some current controversies. Trends in Cognitive Sciences, 5, 156-163.

TsaI, J.-L. (2001). A multichannel PC tachistoscope with high resolution and fast display change capability. Behavior Research Methods, Instruments, \& Computers, 33, 524-531.

Tsai, J.-L., Lee, C.-Y., Lin, Y.-C., Tzeng, O. J.-L., \& Hung, D. L. (2006). Neighborhood size effects of Chinese words in lexical decision and reading. Language \& Linguistics, 7, 659-675.

Tsai, J.-L., LeE, C.-Y., TZeng, O. J.-L., Hung, D. L., \& Yen, N.-S. (2004). Use of phonological codes for Chinese characters: Evidence 
from processing of parafoveal preview when reading sentences. Brain \& Language, 91, 235-244.

Tsai, J.-L., \& McConkie, G. W. (2003). Where do Chinese readers send their eyes? In J. Hyönä, R. Radach, \& H. Deubel (Eds.), The mind's eye: Cognitive and applied aspects of eye movement research (pp. 159-176). Amsterdam: Elsevier.

White, S. J., \& Liversedge, S. P. (2004). Orthographic familiarity influences initial eye fixation positions in reading. European Journal of Cognitive Psychology, 16, 52-78.

White, S. J., \& Liversedge, S. P. (2006). Linguistic and nonlinguistic influences on the eyes' landing positions during reading. Quarterly Journal of Experimental Psychology, 59, 760-782.

White, S. J., RAYner, K., \& Liversedge, S. P. (2005). Eye movements and the modulation of parafoveal processing by foveal processing difficulty: A reexamination. Psychonomic Bulletin \& Review, 12, 891-896.

YAN, G., TIAN, H., BaI, X., \& RAYNER, K. (2006). The effect of word and character frequency on the eye movements of Chinese readers. British Journal of Psychology, 97, 259-268.

Yan, M., Richter, E. M., Shu, H., \& Kliegl, R. (2007, August). Reading Chinese script: The Beijing Sentence Corpus. Paper presented at the 14th European Conference on Eye Movements, Potsdam, Germany.

YAnG, H.-M., \& McConkIE, G. W. (1999). Reading Chinese: Some basic eye-movement characteristics. In J. Wang, A. W. Inhoff, \& H.-C. Chen (Eds.), Reading Chinese script: A cognitive analysis (pp. 207-222). Mahwah, NJ: Erlbaum.

YANG, J., WANG, S., \& RAYNER, K. (2007, August). Do Chinese readers obtain preview benefit from character $n+2$ ? Evidence from eye movements. Paper presented at the 14th European Conference on Eye Movements, Potsdam, Germany.

YANG, S.-N., \& McConkIE, G. W. (2004). Saccade generation during reading: Are words necessary? European Journal of Cognitive Psychology, 16, 226-261.

Zhou, X., Marslen-Wilson, W., Taft, M., \& Shu, H. (1999). Morphology, orthography, and phonology in reading Chinese compound words. Language \& Cognitive Processes, 14, 525-565.

\section{NOTES}

1. The perceptual span in Chinese is smaller than that in English when measured in characters. However, it is intriguing to ask whether this is also true when the extent of the span is measured with respect to word units.

2 . When readers fixate a short word or on the last character of a word of any length, characters (and hence, the word [s] they form) immediately to the right of the fixation point might not be in the parafovea. Nevertheless, the term will be used for convenience.

3. Although the sentences were carefully constructed, there were a few trials on which the constituent character(s) of the preview stimulus (C2 and $\mathrm{C} 3$ ) could combine with the character preceding $(\mathrm{C} 1)$ or following (C4) the preview stimulus to form another word. Two native speakers of Chinese read through a list of character pairs $(\mathrm{C} 1 \mathrm{C} 2$ and $\mathrm{C} 3 \mathrm{C} 4)$ and picked out word-like character pairs. Three items in Experiment 1 and one item in Experiment 2 were identified as ambiguous in this way. For these items, although the ambiguity occurred only in one condition (one out of three preview stimuli in each sentence frame), all the trials associated with these items were excluded from analysis. However, excluding ambiguous trials did not change the effects found in the main analysis.

4. There was neither a main effect of character frequency nor an interaction with preview type on FFD and GD (all $F$ s $<2, p s>.29$ ).

5 . Whether fixation duration before a skip is inflated, as compared with a nonskip, is still a controversial issue in the literature (Drieghe, Rayner, \& Pollatsek, 2005; Kliegl \& Engbert, 2005; Radach \& Heller, 2000). We did not observe consistent results in the present study. Data were classified according to whether or not the target word was fixated during first-pass reading. Nine and 8 participants in Experiments 1 and 2 , respectively, were excluded from analysis because there were conditions in which no target word was skipped during first-pass reading. The item analysis was not conducted because approximately half of the items were excluded due to lack of data after grouping. In Experiment 1, prior fixation duration was significantly longer if the target word was fixated $(231 \mathrm{msec})$ than if it was skipped $(217 \mathrm{msec})\left[F_{1}(1,20)=9.22, M S_{\mathrm{e}}=\right.$ $1,317, p<.01]$. In Experiment 2, prior fixation duration was slightly longer if the target word was fixated $(230 \mathrm{msec})$ than if it was skipped $(225 \mathrm{msec})\left[F_{1}(1,21)=1.10, M S_{\mathrm{e}}=805, p>.30\right]$

6 . It is possible that some skipping may have resulted from oculomotor errors, subsequently addressed by regression. However, the skipping that resulted from randomly mislocated saccades (Nuthmann, Engbert, \& Kliegl, 2005) was presumably equivalent across conditions. Furthermore, the proportion of trials on which the target was skipped and then revisited within two fixations was influenced by the linguistic properties of the preview stimuli. As in note 5, only the participant analysis was conducted, in which the same numbers of participants were excluded from analysis. The probability of immediate regression to the target after skipping was significantly higher for low-frequency words $(27.7 \%)$ than for high-frequency words $(19.3 \%)(p<.05)$. It was also higher in the UN $(29.6 \%)$ and the PS $(30.0 \%)$ conditions than in the ID condition $(11.0 \%)(p<.01$ and $p=.01$, respectively $)$. There was no significant difference between the UN and the PS conditions $(p=1.0)$. There was no interaction between preview type and target frequency $(F<1)$. In Experiment 2, the probabilities of immediate regression to the target after skipping were $12.8 \%, 25.5 \%$, and $18.7 \%$ for the SM, DM, and PS conditions, respectively. However, there was no significant main effect of preview type $(F<2, p>$.18.) Overall, it appears that at least some linguistic processing occurs before and after skipping. The effect of preview type on skipping rate indeed reflects parafoveal word processing, although some skipping may be caused by oculomotor errors. 


\begin{tabular}{|c|c|}
\hline \multicolumn{2}{|r|}{ APPENDIX } \\
\hline \multirow{4}{*}{$\begin{array}{l}\text { Low-Frequency Target Word } \\
\text { Original sentence } \\
\text { Translation }\end{array}$} & Examples From Experiment 1 \\
\hline & \\
\hline & 這位傲慢的公主對其看不順眼的侍從和護衛總是百般地了難。 \\
\hline & $\begin{array}{l}\text { This arrogant princess always acts maliciously to the servants and } \\
\text { guards whom she dislikes. }\end{array}$ \\
\hline Identical-word preview & 這位傲慢的公主對其看不順眼的侍從和護衛總是百般地入難。 \\
\hline Translation & $\begin{array}{l}\text { This arrogant princess always acts maliciously to the servants and } \\
\text { guards whom she dislikes. }\end{array}$ \\
\hline Unrelated-word preview & 這位傲慢的公主對其看不順眼的抗原和護衛總是百般地入難。 \\
\hline Translation & $\begin{array}{l}\text { This arrogant princess always acts maliciously to the antigen and } \\
\text { guards whom she dislikes. }\end{array}$ \\
\hline Pseudoword preview & 這位傲慢的公主對其看不順眼的进莊和護衛總是百般地入難。 \\
\hline Translation & $\begin{array}{l}\text { This arrogant princess always acts maliciously to the boil village } \\
\text { and guards whom she dislikes. }\end{array}$ \\
\hline \multirow{3}{*}{$\begin{array}{l}\text { High-Frequency Target Word } \\
\text { Original sentence } \\
\text { Translation }\end{array}$} & \\
\hline & 市售的假水晶, 多半以玻璃或塑膠製成, 在燈光下會看到氣泡 \\
\hline & $\begin{array}{l}\text { Most of fake crystals sold on the market are made up of glasses or } \\
\text { plastic with bubbles inside if seen by the light. }\end{array}$ \\
\hline Identical-word preview & 市售的假水晶, 多半以玻璃或塑膠製成, 在燈光下會看到氣泡 \\
\hline Translation & $\begin{array}{l}\text { Most of fake crystals sold on the market are made up of glasses or } \\
\text { plastic with bubbles inside if seen by the light. }\end{array}$ \\
\hline Unrelated-word preview & 市售的假水晶, 多半以玻璃或監獄製成, 在燈光下會看到氣泡 \\
\hline Translation & $\begin{array}{l}\text { Most of fake crystals sold on the market are made up of glasses or } \\
\text { jail with bubbles inside if seen by the light. }\end{array}$ \\
\hline Pseudoword preview & 市售的假水晶, 多半以玻璃或傲廠製成, 在燈光下會看到氣泡 \\
\hline \multirow[t]{2}{*}{ Translation } & $\begin{array}{l}\text { Most of fake crystals sold on the market are made up of glasses or } \\
\text { proud factory with bubbles inside if seen by the light. }\end{array}$ \\
\hline & Examples From Experiment 2 \\
\hline Original sentence & 由於家人的支持與鼓勵, 王先生戎菸已經有十年之久了。 \\
\hline Translation & $\begin{array}{l}\text { With family support and encouragement, Mr. Wang has quit smok- } \\
\text { ing for more than } 10 \text { years. }\end{array}$ \\
\hline Same-morpheme preview & 由於家人的支持與鼓勵, 王先生戎除已經有十年之久了。 \\
\hline Translation & $\begin{array}{l}\text { With family support and encouragement, Mr. Wang has quit for } \\
\text { more than } 10 \text { years. }\end{array}$ \\
\hline Different-morpheme preview & 由於家人的支持與鼓勵, 王先生戒備已經有十年之久了。 \\
\hline Translation & $\begin{array}{l}\text { With family support and encouragement, Mr. Wang has guarded } \\
\text { against for more than } 10 \text { years. }\end{array}$ \\
\hline Pseudoword preview & 由於家人的支持與鼓勵, 王先生戒料已經有十年之久了。 \\
\hline Translation & $\begin{array}{l}\text { With family support and encouragement, Mr. Wang has quit / } \\
\text { guarded against material for more than } 10 \text { years. }\end{array}$ \\
\hline
\end{tabular}

Note-Target words and preview stimuli are underscored and marked in boldface. 